\title{
Deontic Pluralism and the Right Amount of Good*
}

\author{
Richard Yetter Chappell
}

\begin{abstract}
Consequentialist views have traditionally taken a maximizing form, requiring agents to bring about the very best outcome that they can. But this maximizing function may be questioned. Satisficing views instead allow agents to bring about any outcome that exceeds a satisfactory threshold or qualifies as "good enough." Scalar consequentialism, by contrast, eschews moral requirements altogether, instead evaluating acts in purely comparative terms, i.e., as better or worse than their alternatives. After surveying the main considerations for and against each of these three views, I argue that the core insights of each are not (despite appearances) in conflict. Consequentialists should be deontic pluralists and accept a maximizing account of the ought of most reason, a satisficing account of obligation, and a scalar account of the weight of reasons.
\end{abstract}

\section{Introduction}

Consequentialism directs us to promote the good. But how much?

Is there a "right amount" of good to produce-a level we need to reach in order to qualify as acting rightly? Maximizers hold

\footnotetext{
*Forthcoming in D. Portmore (ed.), The Oxford Handbook of Consequentialism (OUP). Thanks to Sarah Buss, Anna Edmonds, Emma Hardy, Hrishikesh Joshi, Douglas Portmore, Peter Singer, Michael Slote, and Helen Yetter-Chappell for helpful discussion and comments.
} 
the right amount to be the maximum available to the agent in the circumstances: you act wrongly if an alternative option would have brought about a better outcome. Satisficers identify a less strict threshold, allowing that some suboptimal acts may nonetheless be "good enough". Finally, scalar consequentialists reject the question, simply affirming that acts are better the more good that they produce.

In this paper, I'll question an assumption that underlies this whole debate: that there is a single sense of "rightness" about which these various forms of consequentialism disagree. Sec. 1 discusses maximizing consequentialism, with particular attention to the demandingness objection and to broader structural concerns with identifying rightness and optimality. Sec. 2 explores the case for scalar consequentialism, but then suggests two senses of "rightness" that the scalar theorist lacks good grounds for dismissing. Sec. 3 makes the case for satisficing consequentialism, showing how the view can be defended against three important objections. Finally, sec. 4 explains how deontic pluralism enables us to reconcile these three forms of consequentialism. We can accept an attractive package view that is scalar at core, maximizing about the ought of 
most reason, and satisficing about obligation.

\section{Maximizing}

Maximizing Act Consequentialists hold that an act is right if and only if it produces at least as much value as any other act that the agent could perform at that time. A maximizing approach to ethics can be motivated by appeal to our inclination towards maximizing accounts of practical rationality more generally (Scheffler 1985). Once appropriate practical goals have been identified, it would seem instrumentally rational to act so as to best achieve the relevant goals. ${ }^{1}$

There's no question that from a consequentialist perspective, a suboptimal act is worse than an optimal alternative. So, inasmuch as asking after "the right act" in a situation builds in a linguistic presumption of uniqueness - that there is just one choice among the agent's options which is the right one-a maximizing account

\footnotetext{
${ }^{1}$ Michael Slote has suggested to me a need to distinguish "maximizing" from "optimizing", as one who gives weight to distributional considerations might judge the optimal distribution to be one that does not maximize the amount of good being distributed. However, once we recognize that the egalitarian consequentialist takes equality itself to be of value, we can see that maximizing the amount of some resource without regard for distribution is not necessarily the same as maximizing the value of the overall state of affairs. It is the latter that I take the maximizing consequentialist to be committed to. "Maximizing" in this sense is perfectly compatible with egalitarian or other distributional concerns.
} 
of right action can come to seem very natural to a consequentialist.

Nonetheless, there are reasons to be wary of insisting that consequentialism take a maximizing form. Despite sometimes speaking of "the right act", we don't generally think that morality is so restrictive as to rule out almost every option we have in any given situation. We expect morality to rule out morally unacceptable options, and leave us free to choose amongst the remainderincluding, typically, many options that are considered acceptable despite falling short of moral perfection. Maximizers, by contrast, are committed to denying any space for such moral autonomy (though they can certainly defend the social practice of autonomy, given that trying to force people to act maximally well would plausibly backfire). We may choose how to break ties between morally optimal options, if there happens to be more than one, but are given no further permissible options beyond that.

By so restricting our practically permissible options, maximizing consequentialism also proves conceptually restricting. For, in fleshing out the structure of our moral options, common sense recognizes conceptual room for the supererogatory, i.e., acts that go "above and beyond" the call of duty. This possibility is entirely 
precluded by a maximizing account of our duties. If required to always do the best, there is no room left for us to do better than the minimum required.

Further, by requiring actions that are intuitively supererogatory, maximizers are subject to the objection that their conception of morality is overly demanding, or places unreasonable demands on agents. This objection is standardly developed in relation to the demands of beneficence, and especially Singer (1972)'s view that we should give to the point of marginal utility-where any further donation would hurt us more than it would help the recipients.

How weighty should consequentialists find the demandingness objection? Norcross (2020, chap. 2.2) questions the reliability of anti-demandingness intuitions on the grounds of their being obviously self-serving for the culturally influential. Sobel (2007) counters it differently, arguing that the demandingness objection presupposes, rather than supports, non-consequentialist asymmetries between (e.g.) action and inaction. After all, however demanding maximizing consequentialism may seem for the affluent, we may wonder why alternative theories are not seen as even more demanding for the poor, given the much greater costs that will 
befall them if the affluent fail to give much aid (Murphy 2000, 55). Ordinary demandingness intuitions are evidently not tracking a neutral evaluation of the (net) costs to people of general compliance with a theory. This may support Norcross' suspicions, and lead us to doubt whether we have principled reasons to care about whatever it is that they are tracking.

Defenders of the demandingness objection respond by stressing the significance of self-imposed costs as raising distinctive moral questions. We may ask whether agents have sufficient reason to comply with a putative moral demand that would prove very costly to them (Woollard 2016), or whether they would warrant blame should they fail to so comply (McElwee 2017). Such questions aren't applicable to moral patients when they suffer costs imposed from without. Morality does not, in this instance, demand that the sufferers do anything. And so the distinctive questions of moral demandingness simply don't arise in relation to such costs.

This account allows us to make sense of the special role that selfimposed costs play in our assessments of demandingness. But it remains an open question whether we have good grounds to trust the underlying intuitions that would permit the affluent to neglect 
the needs of the poor. The critics of maximization may thus do better to shift their focus away from the specific demands of beneficence, and instead emphasize the purely structural objections to maximizing consequentialism.

As Railton $(1988,407)$ notes, "it seems inconsistent with anything like our ordinary understanding of 'morally right' to say that the boundary separating the right from the wrong is to be sharply drawn infinitesimally below the very best action possible. [...] 'Wrong' comes into clear application only when we reach actions far enough below normal expectations to warrant real criticism or censure." McElwee $(2017,97)$ similarly observes that "we do not judge that someone warrants feelings of blame and guilt simply for acting morally suboptimally." It's one thing to hold that extreme poverty and suffering are morally intolerable, and so can generate extreme demands. It's quite another to insist upon the intolerability of suboptimality per se. Imagine getting worked up over a lost penny in Utopia. The view begins to sound literally insane.

Maximization may also face embarrassment when confronted with its structural analogy to the minimalist view on which only the 
very worst option (among all available) is held to be wrong (cf. Slote $1985,77)$. Although less silly-seeming than this opposite extreme, maximization may start to seem less like a well-motivated "default" form for consequentialism to take, and more like a hasty graft of consequentialist ideas upon an incompatible (or at least ill-fitting) base of deontic concepts. For while consequentialists may all agree that a value-maximizing option is best, or what we've most moral reason to choose, it's entirely obscure what further claim (if any) the maximizer means to make by insisting that the best option is also obligatory. ${ }^{2}$

\section{Scalar Consequentialism}

Suspicions regarding the traditional deontic concepts may naturally lead consequentialists to jettison them in favor of simply evaluating actions on a scale from better to worse. Howard-Snyder $(1994,110)$ identifies the heart of consequentialism as the claim that, "The better a state of affairs, the more moral reason an agent has to produce it." There's no obvious motivation internal to con-

\footnotetext{
${ }^{2}$ Lazari-Radek and Singer (2014, 334), for example, explicitly take the question "what ought I to do?" to be equivalent to "What do I have most reason to do?"
} 
sequentialism for drawing a line between 'right' and 'wrong' at any particular point on the scale. Whether maximal, minimal, or something in between, the placement of such a line on the scale from best to worst action may seem unacceptably arbitrary. This arbitrariness worry motivated the original development of scalar consequentialism in Slote (1985, chap. 5), and also features in the most recent development of the view by Norcross (2020, chap. 2.3, drawing from his 2006). And it is a fair worry as far as it goes. But I think it actually stems from a deeper problem, namely, a lack of clarity regarding what (for consequentialists) any such line is supposed to even signify. ${ }^{3}$ Once we are clearer on what the line between right and wrong is meant to signify, we may find that the question of where to draw it is more easily answered.

Norcross assumes that deontic binaries would create extra reasons, in a way that's incompatible with consequentialism. Consequentialists should certainly prefer that Joe give an extra $\$ 500$ to

\footnotetext{
${ }^{3}$ Anscombe (1958) famously raised similar worries, albeit in a different dialectical context, about the intelligibility of traditional deontic concepts in modern moral philosophy. Railton $(1988,408)$ suggests that act utilitarians use 'right' as a term of art, which strikes me as robbing their claims about rightness of any substance. Howard-Snyder $(1994,121)$ aptly observes, "Once you see the consequentialist as saying that there is more moral reason to produce A than B it is hard to see what else she could be saying when she says that the agent ought to or is required to produce A."
} 
effective charities rather than Jane giving an extra $\$ 499$, regardless of whether Jane's increment would bump her over the line from 'wrong' to 'right'. But this is just to observe that consequentialists care exclusively about promoting value, and so have no independent concern for the deontic status of an action (Lawlor 2009, 104). We can't conclude from this that actions don't have deontic statuses, since making an evaluative difference is not, in general, a precondition for being a real property. ${ }^{4}$ Nonetheless, we may at least wonder, with Norcross, what the significance of an act's deontic status (as right or wrong) is supposed to consist in if it makes no essential difference to what others should do or prefer.

Here I think there are at least two possible answers worth considering. First, if we accept a distinction between moral and nonmoral (e.g. prudential) reasons, we might take an act's deontic status to reflect how these reasons balance out. Along these lines, Lawlor $(2009,106)$ suggests that beneficent acts might be morally required by a cost-sensitive form of consequentialism just when the moral reasons to do the act outweigh the agent's (dispropor-

\footnotetext{
${ }^{4}$ We might also question whether a third party's attitudes are the right place to look for moral significance here (Lang 2013, 86). The deontic status of Jane's action may have some significance for Jane even if it is not of interest to others, after all.
} 
tionately weighted) prudential reasons against. On this view, while some altruistic sacrifice may be required of us, there is some point at which the personal sacrifice becomes sufficiently great that our prudential reasons to favor ourselves trump our moral reasons to promote the impartial good. Portmore (2011, chap. 5) further develops such a dual-ranking structure for act consequentialists. On such accounts, the line between right and wrong marks something significant about the agent's overall reasons, without creating extra reasons or otherwise conflicting with core consequentialist tenets.

Alternatively, rather than treating an act's deontic status as a function of the agent's various reasons for action, we might take it to reflect what reactive attitudes are warranted by the agent's so acting (McElwee 2010a). I think it is especially natural to understand talk of "obligation" in this way. Thus, for example, Jane's rightmaking increment could simply have significance for whether she warrants certain negative reactive attitudes, without that giving her any more reason than Joe has to act.

A potential advantage of this approach over dual-ranking is that we aren't committed to distinguishing distinctively moral from non-moral reasons, or to giving disproportionate weight to 
an agent's partial interests. A further advantage to understanding obligation in terms of reactive attitudes will emerge in sec. 3.3. (One could also opt to combine dual-ranking with the reactiveattitudes account of obligation, so while I discuss them separately, I do not mean to suggest that they are strictly exclusive alternatives.)

Of course, as Norcross (2020, chap. 2.4.) notes, consequentialists shouldn't understand wrongness in terms of whether others ought to punish or express blame towards the agent, as such acts are themselves open to consequentialist assessment, which may diverge radically from our assessment of the original action. Conceivably, it could even be useful in some circumstances to express blame towards someone for acting optimally (perhaps a trickster demon would reward us for behaving so perversely). So the usefulness of expressing blame is just clearly irrelevant to any fair normative assessment of the original action. But this doesn't undermine an analysis of wrongness in terms of blame-worthiness, for whether it is useful to express blame is a completely separate matter from whether blame (understood as a negative reactive attitude) is warranted, ${ }^{5}$ in much the same way that whether it is

\footnotetext{
${ }^{5}$ McElwee (2010b, 399) has also emphasized this point in response to Norcross.
} 
useful to express fear in some situation is a completely separate matter from whether fear is warranted.

Consequentialists have historically been loathe to acknowledge any such independent norms of fittingness for our reactive attitudes, but it's not clear that this traditional aversion is wellmotivated. We wouldn't normally think of consequentialism as being in conflict with an epistemologist's claims about our (evidential) reasons for belief, after all. Insofar as there are belief-related actions we can take (e.g. brainwashing ourselves into acquiring a new belief, or verbally expressing some existing belief), consequentialist assessment of those actions is perfectly possible. Nonetheless, whether a belief is rationally warranted, or supported by the evidence, is just a completely separate question from whether it is, in practical terms, worth either inculcating or expressing. But now notice that the same is true of emotions and reactive attitudes. A plausible non-consequentialist account of when these states are rationally warranted or fitting can comfortably exist alongside consequentialist norms for action (Chappell 2012). ${ }^{6}$ It may then

\footnotetext{
${ }^{6}$ We can (of course) evaluate these states, like anything else, in terms of their contributory value: whether their existence makes the overall state of affairs better or worse, and to what extent. Consequentialists will typically regard this question of value as more important than assessments of rational warrant (we should, for example, prefer that people have useful attitudes than that they have
} 
turn out that we sometimes ought to acquire irrational attitudes, but such "rational irrationality" is a familiar possibility since Parfit (1984, chap. 1). So I see no fundamental barrier to consequentialists accepting an independent account of blameworthiness. ${ }^{7}$ Such an account could in turn ground an account of wrongness that is (contra Norcross) significant without creating extra deontic reasons.

Our discussion so far suggests that the case for (or against) scalar consequentialism really depends upon the larger question of what sense consequentialists can give to a division between right and wrong actions. That's the conclusion that I, at least, am drawn

warranted ones). Still, theoretical clarity requires us to recognize the two distinct dimensions of normative assessment here. Consequentialists will hold that the two dimensions coincide in the case of actions: the more useful or worthwhile the act, the more objectively warranted it is to perform. (That's what I mean by "consequentialist norms for action": accounting for our normative reasons for action in terms of the value or desirability of so acting.) When assessing mental states, by contrast, we should recognize that the two may come apart. This is because whether a propositional attitude is warranted depends upon whether its propositional content or object is fitting to the type of attitude that it is, which is clearly different from simply evaluating the consequences of possessing the attitude in question. Note that acts don't allow for any such clearcut distinction between "state" and "object", which may partly explain why it's so much more natural to think that acts are warranted insofar as they produce desirable outcomes.

${ }^{7}$ Independent of the consequences of possessing the blaming attitude, that is. There will still be important connections between our normative theory and our account of blameworthiness. Even supposing that blameworthiness is to be accounted for in terms of quality of will, consequentialists are likely to differ from others in how we interpret this. We may judge some beneficent acts of utilitarian sacrifice-e.g., killing one to save five in the notorious Trolley Bridge case - to be well-motivated, when a deontologist would disagree. 
towards. Some, however, have suggested rejecting scalar consequentialism on the independent basis that it fails to be sufficiently action-guiding.

\subsection{Practical Guidance}

In his original presentation of the idea of scalar morality, Slote (1985, chap. 5.3) raised the worry that by failing to specify which actions are right or wrong, such a view might seem to leave out something essential to a full account of morality. Against this, Slote notes that even non-scalar accounts don't settle all practical questions in circumstances where they give us multiple permissible options. Moreover, Slote suggests, a highly morally motivated agent (who always prefers morally better options over morally worse ones) could find plenty of guidance in the comparative verdicts yielded by scalar morality. It may be true that someone specifically motivated to do the least that morality requires of him could no longer be guided by this specific desire. But if this is really the only moral motivation that the agent has, we may be more inclined to judge that the problem here lies with the agent rather than with scalar moral theories. 
An alternative response available to the scalar theorist would be to offer a scalar account of right(er) and wrong(er). Sinhababu (2018) suggests that scalar morality can actually offer richer guidance than traditional approaches, as it no longer lumps together (e.g.) mildly bad and truly atrocious options as "equally wrong". While insisting that there is no fundamental significance to the dividing point between right and wrong actions, Sinhababu—following Norcross (2005) - offers a contextualist account of rightness as what's better than some salient alternative or amount of goodness. This allows the scalar consequentialist to engage in "rightness"-talk, but in a way that makes the line drawn between 'right' and 'wrong' merely conventional.

I find it a bit unclear what is achieved by this maneuver. Because this constructed boundary between 'right' and 'wrong' lacks normative significance, it would seem a mistake for agents to care about it. Insofar as we want fine-grained guidance, this may be found in the scalar theorist's evaluations of options as better or worse (to greater or lesser degrees). Repeating these judgments using deontic vocabulary doesn't seem to add anything. So, rather than offering guidance via scalar 'rightness', scalar theorists might 
do better to simply insist that agents' moral motivation should be responsive to the scalar evaluative differences upon which their theory rests.

Insofar as we feel that something important is left out of the scalar account, a merely conventional reconstruction of deontic language seems unlikely to help. For what those dissatisfied by the scalar approach really want, presumably, is for our moral theory to identify a principled line of minimal decency below which we must not fall (on pain of warranting negative reactive attitudes, perhaps). For that, we must move beyond the resources of a purely scalar account of morality.

\section{Satisficing}

Slote $(1984,140)$ introduced philosophers to the idea of satisficing consequentialism: "that an act might qualify as morally right through having good enough consequences, even though better consequences could have been produced in the circumstances." That is, rather than insisting that the best outcome be produced,

\footnotetext{
${ }^{8}$ Though the broader concept of satisficing first emerged in the economics literature (Simon 1955).
} 
the satisficer identifies a (non-maximal) value threshold at which outcomes qualify as "good enough". They then affirm that any act is permissible so long as it brings about some such sufficiently good outcome. Only outcomes below this value threshold are impermissible to produce.

Slote's own version of the view is quite radical, licensing what Pettit $(1984,172)$ calls "unmotivated submaximization": picking a worse option when a better one has been identified and is available at no greater cost. This gives rise to one of the three central objections to satisficing consequentialism: the problem of gratuitous suboptimality.

\subsection{Gratuitious suboptimality}

Mulgan $(1993,125)$ invites us to imagine that, faced with the option to magically save any number of people from poverty, Achilles deliberately chooses a number that is smaller than the total number of impoverished people, insisting that the resulting outcome is "good enough". Achilles' action seems clearly wrong, since he could just as easily have saved a greater number of people from poverty, at no cost. Satisficing consequentialism thus seems at risk 
of violating a maximally weakened variant of Singer (1972)'s sacrifice principle: If you can prevent something bad from happening, without sacrificing anything whatsoever, you ought, morally, to do it!

Bradley (2006) extends the problem by presenting cases in which satisficing consequentialism would seem to allow agents to gratuitously obstruct an optimal outcome that would have occurred without their maleficent interference. But surely no consequentialist should wish to license actions that so gratuitously steer us away from better outcomes.

A natural response for satisficers is to insist that gratuitously suboptimal outcomes fail to qualify as "good enough" in context (Turri 2005). Rogers (2010) develops a complicated form of satisficing consequentialism that meets this desideratum by only permitting suboptimal choices when the morally better alternatives are comparatively costly to the agent. Chappell (2019) similarly argues that the best structure for a satisficing theory to adopt is one of constrained maximization, according to which (roughly speaking) agents should do the best they can without suffering undue burden. This makes clear that gratuitous suboptimality is never permitted. 
And it yields a compelling account of supererogation as choosing to surpass the demandingness-moderating constraints in order to achieve even better results. On such an account, the key work for a satisficing theory is to flesh out what counts as acceptable vs. undue burdens.

\subsection{Arbitrariness}

This leads us to what may be the most obvious challenge for satisficers, namely, identifying —on a principled basis—where to draw the line for what counts as "good enough". Is there any nonarbitrary way to do this? As suggested in sec. 2, I think we can best make progress here by clarifying what we have in mind when asking which acts are good enough-good enough to secure what status, exactly? Some form of minimal decency, presumably. But as we saw, there are (at least) two ways of fleshing out this idea: (i) directly in terms of our overall reasons for action, or (ii) indirectly in terms of warranting reactive attitudes.

If we understand minimal decency in terms of giving sufficient weight to moral reasons (in relation to the weight we give to our non-moral reasons), we need our complete theory of practical 
reason to specify what those appropriate weightings are. Call this the "rationalist" view of moral rightness. If there are such varieties of reasons, there's presumably a fact of the matter about their comparative strengths or weights. Satisficers could then appeal to such facts in order to determine, non-arbitrarily, what outcomes are morally "good enough". These outcomes are "good enough" in the sense that any morally better alternatives are subject to countervailing non-moral reasons that are sufficiently weighty as to rationally justify the agent's refusal to choose them.

Alternatively, on a "sentimentalist" understanding of minimal decency in terms of (say) demonstrating sufficient quality of will as to render the agent blameless, ${ }^{9}$ we instead need an account of blameworthiness (or the fittingness conditions for reactive attitudes) to specify the minimum baseline for what counts as adequate moral concern. Once we have such an account, Chappell (2019, 256-57) argues that the satisficing consequentialist can coopt it to provide a principled specification of how much effort

\footnotetext{
${ }^{9}$ This is a slight oversimplification. It should be possible to do the right thing for the wrong reasons, after all, and hence act permissibly but in a way that is blameworthy. So the connection must be slightly looser than presented above. It would be better to understand permissible acts as those that are compatible with possessing adequate quality of will, given all relevant information. But the precise details aren't essential for our purposes.
} 
(or burden) morality can require of us. First we ask how much effort an agent in certain circumstances must be willing to expend in pursuit of the general good in order to qualify as adequately concerned (according to our independent account of quality of will). Then we can claim that the agent is required to bring about the best results they can without having to exceed that level of effort (excessive gains being supererogatory).

Either way, the satisficer's line between right and wrong can be drawn in a principled way. It simply requires drawing upon resources that go beyond the core consequentialist theory: appealing to either non-moral practical reasons or else fitting attitudes.

\subsection{Options without constraints}

Our final challenge for satisficing consequentialism is more extensional than structural. The worry is that it risks licensing morally atrocious actions. It's a familiar point that, given its rejection of the doing/allowing distinction and associated deontic constraints, traditional act consequentialism is apt to license actions that strike many as intuitively wrong: killing one as a means to saving five, for example. But at least the maximizer has a compelling response 
available: such acts are necessary for bringing about the best available outcome. However bad it may be for one to die, it would surely be worse for five to do so.

The satisficing consequentialist has no such easy answer. Consequentialism ascribes no essential significance to the distinction between doing and allowing, or between harming and failing to benefit. So if satisficing consequentialism sometimes permits us to suboptimally let others die, it seems that it must equally permit us to suboptimally murder (Mulgan 2001; cf. Kagan 1984, 251). This is a serious problem for the view. After all, however intuitive it may be to say that we are allowed to refrain from saving a life if that would cost us thousands of dollars, that surely isn't worth being stuck with the corresponding verdict that it's permissible to kill someone merely for personal gain.

This problem may be especially pressing for the rationalist satisficer, who is committed to their deontic verdicts tracking the agent's overall normative reasons. They may, of course, appeal to typical consequentialist strategies for avoiding counterexamples, e.g. noting the risk of worse outcomes if agents felt free to disregard deontic constraints. They might thus recommend that 
agents adopt a decision procedure that disallows these objectively justified actions. But the mere fact that their view holds suboptimal killings to be objectively justified is arguably disqualifying, regardless of whether they endorse or reject a decision procedure that encourages agents to be guided by this normative fact.

The sentimentalist satisficer may be better placed to weaken the force of the objection in a couple of ways. First, they can note that their deontic verdict of permissibility doesn't entail that the agent has most overall reason to act in this way. It's open to sentimentalist satisficers to insist that agents always have most reason to act optimally, such that suboptimal acts (even when blameless) constitute a kind of mistake. So that's something. But it isn't a very satisfying response, as we would ordinarily think that killing someone for (comparatively morally insignificant) personal gain is a paradigm example of a blameworthy (and not merely rationally imperfect) act.

A better route for the sentimentalist, I think, is to appeal to features of human psychology that can explain why killing typically reveals a worse quality of will than merely letting die. The relevant psychological facts concern what we find salient. We do not gen- 
erally find the millions of potential beneficiaries of charitable aid to be highly salient. Indeed, people are dying all the time without impinging upon our awareness at all. A killer, by contrast, is (in any normal case) apt to be vividly aware of their victim's death. So killing tends to involve neglecting much more salient needs than does merely letting die. ${ }^{10}$

Next, note that neglecting more salient needs reveals a greater deficit of good will (Chappell and Yetter-Chappell 2016, 452). This is because any altruistic desires we may have will be more strongly activated when others' needs are more salient. So if our resulting behavior remains non-altruistic even when others' needs are most salient, that suggests that any altruistic desires we may have are (at best) extremely weak. Non-altruistic behavior in the face of less salient needs, by contrast, is compatible with our nonetheless possessing altruistic desires of some modest strength-and possibly sufficient strength to qualify as "adequate" moral concern.

Putting these two facts together, then, secures us the result that suboptimal killing is more apt to be blameworthy (and hence

\footnotetext{
${ }^{10}$ There are exceptions, e.g. watching a child drown in a shallow pond right before your eyes-but those are precisely the cases in which we're inclined to judge letting die to be morally comparable to killing.
} 
impermissible in sentimentalist terms) than comparably suboptimal instances of letting die. It's a neat result for sentimentalist satisficers that they're able to secure this intuitive result without attributing any fundamental normative significance to the distinction between killing and letting die.

\section{Reconciliation}

In the debate between maximizers, satisficers, and scalar consequentialists, we've seen that much hinges on our understanding of what any putative distinction between right and wrong is supposed to signify. Given the various possibilities explored already in this paper, we may wonder whether participants in this debate have always had the same shared concept in mind. That is, we might question whether there is any single determinate "ordinary concept of rightness" for this debate to be about. If ordinary usage vacillates or otherwise underdetermines what is really meant here, the resulting "ordinary concept" may be too amorphous to make sense of the present dispute. As we've seen, it's especially unclear

what maximizers have in mind with their "rightness" talk, and 
whether there's really any substantive disagreement to be found between them and scalar consequentialists.

This diagnosis opens up an attractive new option for resolving the debate in a more ecumenical fashion. We may become deontic pluralists, accepting a variety of different deontic concepts (different senses of right, ought, etc.), and see maximizers, satisficers, and scalar consequentialists as offering complementary insights into different parts of the moral landscape.

\subsection{Deontic Monism}

To clear the way for deontic pluralism, it will be helpful to assess the rival view that there is a single, privileged sense of rightness. Given the multiple possible ways of constructing deontic terms that we've discussed already in this paper, the only clear basis I can see for insisting upon deontic monism would be if one held that there was a primitive, indefinable sense of "right" and "wrong", which could take linguistic priority over the various definable senses of these terms. Parfit $(2011,165)$ seems to affirm such a view, using the phrase "mustn't-be-done" to express what he calls an "indefinable version of the concept wrong". 
I think there are good reasons for consequentialists to reject such a view. To begin with, the idea of a primitive property of mustn't-be-done seems unacceptably mysterious, in contrast to more familiar normative properties such as counting in favor of an action, or rationally warranting some attitude. Absolutist moral theories such as Kantianism might well make better sense of such a property, so I don't here mean to suggest that it is unacceptably mysterious in some theory-neutral sense that counts against those other theories. I just mean that a primitive notion of mustn't-be-done seems mysterious specifically in the context of consequentialism. It seems like a bad fit for the theory. It's not the kind of property that I'd expect consequentialists to comfortably countenance.

Indeed, the arguments for scalar consequentialism make a lot more sense if we take primitive rightness to be their target. The arbitrariness objection returns in full force, since without an analytic connection to other normatively significant properties, there would seem no basis for drawing the line between right and wrong at any particular point (maximal or otherwise) on the scale from better to worse acts. Perhaps connections could be restored by ac- 
counting for other properties, such as blameworthiness, in terms of primitive rightness. But this would at the very least raise tricky methodological issues about the legitimacy of using the downstream property to fix the location of the upstream one.

Moreover, insofar as I have any grip at all on the concept of mustn't-be-done, it seems like it should mark a point of significant discontinuity in the strength of one's moral reasons to act, but this is difficult to reconcile with the continuous scale of value that our acts can realize. It also seems like bystanders should be specially concerned to prevent the occurrence of acts that mustn't be done. But such claims are incompatible with consequentialism, as we saw in sec. 2.

Finally, I think the attractiveness of the deontic pluralist package presented below gives us further reason to reject this (less attractive) rival. So let us move on now to presenting the positive view.

\subsection{Deontic Pluralism}

We may begin by affirming that a scalar account of our moral reasons constitutes the core of consequentialism. On this view, the 
extent to which one has a moral reason to $\phi$ is purely a function of how good the world would be if one were to $\phi .{ }^{11}$ The better the outcome, the more reason we have to produce it (Howard-Snyder 1994, 110).

Further, as we saw in sec. 4.1, scalar consequentialists correctly reject primitive rightness. This is an important insight that (perhaps surprisingly) clears the way for plausible forms of maximizing and satisficing consequentialism to emerge. For while we should reject primitive or indefinable deontic concepts, we may supplement our core scalar view with various definable deontic concepts, including ones that are defined in terms that are normatively significant rather than merely conventional.

First we may consider a couple of deontic concepts that are definable in terms of our reasons for action. There's an obvious sense in which we (ideally) morally ought to do whatever we have most moral reason to do. Maximizing consequentialism may be most comfortably understood as answering the question of what we ought, in this aspirational sense, to do (Norcross 2020, chap. 2.9). There would seem no reason for any consequentialist to

\footnotetext{
${ }^{11}$ Thanks to Doug Portmore for suggesting this formulation.
} 
deny the maximizer's view, so understood. More interestingly, some might affirm the hegemonic thesis that this is also what we have most overall reason to do (contra dual-rankers and others who posit weighty non-moral reasons). Addressing what we have most overall reason to do is, after all, much more substantive and interesting than merely addressing some narrower class of "moral" reasons that might yet be outweighed by other considerations. So I would encourage serious consequentialists to defend this more ambitious maximizing view.

Next, as we saw in secs. $3.2-3.3$, there is a sentimentalist understanding of wrongness in terms of blameworthiness that meshes very nicely with satisficing consequentialism. This allows consequentialists to present a less demanding account of our obligations, and also to account for the intuitive significance of the doing/allowing distinction in an appropriately derivative fashion.

Consequentialists may thus avail themselves of multiple deontic concepts. But you may wonder whether all of them are really needed. Perhaps we can identify one that has normative priority in virtue of its special relevance to first-personal deliberation-i.e., as the sense of 'ought' that a conscientious agent has in mind when 
they ask themselves, "What ought I to do?"

There are independent grounds for doubting that the deliberative question has a suitably fixed and determinate meaning. ${ }^{12}$ Even just focusing on the choice between the ought of most reason and the ought of minimal decency (or blamelessness), we aren't obviously forced in either direction here, e.g. by the constitutive norms of agential deliberation. Some agents in some contexts are particularly concerned to at least meet the standards for minimal decency, whereas others are more morally ambitious. We can certainly say that it's better for agents to do better. But it isn't clear that there's much more we can say beyond this trivial evaluative observation. In particular, I see no clear basis for insisting that there is just one proper aim of deliberation.

On the contrary, I think we can make good sense of why both standards have a limited place in our normative lives. The ought of most reason is perhaps the most obviously significant. It picks out the best choice for us to make, the option which is most welljustified, providing an ideal standard to which it makes sense to

\footnotetext{
${ }^{12}$ See https://www.philosophyetc.net/2009/06/deliberative-question.html for discussion of how the relativistic aspects of our assertoric practices here undermine the philosophical significance of the deliberative question.
} 
aspire. (Of course, whether it is practically useful or advisable to aspire to it in any given situation is a further, empirical question. Some may just be disheartened were they to try. But I don't take such practical concerns to undermine the in-principle aptness of the aspiration, which is what I'm concerned with here.)

The practical relevance of the ought of minimal decency may be supported in two ways. First, it arguably has more third-personal significance. We properly hold others to account when their actions fall below the baseline of minimal decency and into the realm of the blameworthy. Although it's nice when they do better than the minimum required, we typically don't feel that it's our place to probe too deeply into such matters, or to evaluate them too closely. ("How much exactly did you give to charity last year?")

Secondly, the baseline of minimal decency may have firstpersonal significance given our nature as flawed agents who regularly (perhaps even inevitably) do less than the absolute best. Given that we must, practically speaking, make our peace with often failing to meet the ideal standard, it would seem helpful to have a "backup" standard below which we feel we must not fall. The ought 
of minimal decency seems a natural fit for this role. (Again, I don't mean that it is necessarily the empirically most useful guide for us to follow, but just that it makes theoretical sense as a principled basis for ruling out some options as "unacceptably bad" without committing ourselves to acting perfectly.)

All three components of our deontic-pluralist consequentialist package thus strike me as important for an apt moral outlook. It makes sense to aspire to do the best, while recognizing and accepting the reality that, as flawed agents, we will typically fall short. And it makes sense to have a firmer commitment to maintaining a level of at least minimal decency, rather than being willing to plummet to any moral depths without limit. Then, between these two principled standards lies a continuous scale of more-or-less demanding standards that we might choose to target. To help guide us in this choice, we can appreciate that the more good we achieve, the better. But beyond that, there is no authoritative metastandard out there to tell us how high to aim. ${ }^{13}$ This observation

\footnotetext{
${ }^{13}$ Though some consequentialists may naturally be drawn to the practical meta-standard of asking what standard is such that our aiming at it would have the best consequences? That's of some practical interest, but lacks the special authority of identifying the uniquely fitting or appropriate standard to aim at. It is also, notably, not necessarily the meta-standard such that our employing it would have the best consequences.
} 
may be taken to reinforce the scalar "core" of the pluralist view I've defended.

We've seen that deontic pluralism provides consequentialists with the opportunity to accept an attractive package of views: scalar at core, maximizing about the ought of most reason, and satisficing about obligation. Notably, these specific scalar, maximizing, and satisficing claims do not conflict. Moreover, each seems to have a place in our thinking about the normative terrain. So we can, and arguably should, accept all three. Our overall consequentialist theory may be the stronger for it. 


\section{References}

Anscombe, G. E. M. 1958. “Modern Moral Philosophy.” Philosophy 33 (124): 1-19.

Bradley, Ben. 2006. “Against Satisficing Consequentialism.” Utilitas 18 (2): 97-108.

Chappell, Richard Yetter. 2012. "Fittingness: The Sole Normative Primitive." Philosophical Quarterly 62 (249): 684-704.

-—-. 2019. "Willpower Satisficing." Noûs 53 (2): 251-65.

Chappell, Richard Yetter, and Helen Yetter-Chappell. 2016. "Virtue and Salience." Australasian Journal of Philosophy 94 (3): 449-63.

Howard-Snyder, Frances. 1994. "The Heart of Consequentialism.” Philosophical Studies 76 (1): 107-29.

Kagan, Shelly. 1984. "Does Consequentialism Demand Too Much? Recent Work on the Limits of Obligation." Philosophy and Public Affairs 13 (3): 239-54.

Lang, Gerald. 2013. "Should Utilitarianism Be Scalar?” Utilitas 25 (1): 80-95. 
Lawlor, Rob. 2009. "The Rejection of Scalar Consequentialism.” Utilitas 21 (1): 100-116.

Lazari-Radek, Katarzyna de, and Peter Singer. 2014. The Point of View of the Universe: Sidgwick and Contemporary Ethics. Oxford University Press.

McElwee, Brian. 2010a. "Should We de-Moralize Ethical Theory?" Ratio 23 (3): 308-21.

- - . 2010b. "The Rights and Wrongs of Consequentialism." Philosophical Studies 151 (3): 393-412.

- - . 2017. "Demandingness Objections in Ethics." Philosophical Quarterly 67 (266): 84-105.

Mulgan, Tim. 1993. “Slote’s Satisficing Consequentialism.” Ratio 6 (2): $121-34$.

- - . 2001. "How Satisficers Get Away with Murder." International Journal of Philosophical Studies 9 (1): 41-46.

Murphy, Liam. 2000. Moral Demands in Nonideal Theory. Oxford University Press.

Norcross, Alastair. 2005. "Contextualism for Consequentialists." 
Acta Analytica 20 (2): 80-90.

—-—. 2006. "Reasons Without Demands: Rethinking Rightness."

In Contemporary Debates in Moral Theory, edited by James Dreier.

Malden, MA: Wiley-Blackwell.

-- . 2020. Morality by Degrees: Reasons Without Demands. Oxford University Press.

Parfit, Derek. 1984. Reasons and Persons. Oxford: Clarendon Press.

- - . 2011. On What Matters: Volume One. Oxford: Oxford University Press.

Pettit, Philip. 1984. “Satisficing Consequentialism.” Proceedings of the Aristotelian Society, Supplementary Volumes 58: 165-76.

Portmore, Douglas W. 2011. Commonsense Consequentialism: Wherein Morality Meets Rationality. Oxford University Press.

Railton, Peter. 1988. "How Thinking About Character and Utilitarianism Might Lead to Rethinking the Character of Utilitarianism." Midwest Studies in Philosophy 13 (1): 398-416.

Rogers, Jason. 2010. "In Defense of a Version of Satisficing Consequentialism." Utilitas 22 (2): 198-221. 
Scheffler, Samuel. 1985. "Agent-Centred Restrictions, Rationality, and the Virtues." Mind 94 (375): 409-19.

Simon, Herbert A. 1955. "A Behavioral Model of Rational Choice." The Quarterly Journal of Economics 69 (1): 99-118.

Singer, Peter. 1972. "Famine, Affluence, and Morality." Philosophy and Public Affairs 1 (3): 229-43.

Sinhababu, Neil. 2018. "Scalar Consequentialism the Right Way." Philosophical Studies 175 (12): 3131-44.

Slote, Michael. 1984. "Satisficing Consequentialism." Proceedings of the Aristotelian Society, Supplementary Volumes 58: 139-63.

- - . 1985. Common-Sense Morality and Consequentialism. Routledge \& Kegan Paul.

Sobel, David. 2007. “The Impotence of the Demandingness Objection." Philosophers' Imprint 7 (8): 1-17.

Turri, John. 2005. "You Can't Get Away with Murder That Easily: A Response to Timothy Mulgan.” International Journal of Philosophical Studies 13 (4): 489-92.

Woollard, Fiona. 2016. "Dimensions of Demandingness." Proceed- 
ings of the Aristotelian Society 116 (1): 89-106. 